\title{
Diferenças no consumo alimentar de adolescentes na Região Centro-Oeste e outras regiões brasileiras
}

\section{Differences in dietary intake of adolescents in the Midwest and other Brazilian regions}

Ruanda Pereira Maia ${ }^{1}$

Stefanie Eugênia dos Anjos Coelho Kubo?

Muriel Bauermann Gubert ${ }^{\dagger}$

1 Departamento de Nutrição, Faculdade de Ciências da Saúde, Universidade de Brasília. Brasília, DF, Brasil.

Fontes de financiamento e suporte institucional: Esse estudo faz parte da pesquisa "Mapeamento da cultura alimentar da população adolescente nas capitais brasileiras e Distrito Federal", com financiamento do Conselho Nacional de Desenvolvimento Científico e Tecnológico - CNPq (processo - $n^{0} .559384 / 2010-6$ ). A pesquisa também contou com apoio do Ministério da Educação e Secretarias de Educação de cada estado e município visitados.

Correspondência / Correspondence Ruanda Pereira Maia Departamento de Nutrição, Faculdade de Ciências da Saúde, Universidade de Braślia Campus Universitário Darcy Ribeiro 70910-900 Brasília, DF, Brasil E-mail:ruanda_maia@yahoo.com.br

\section{Resumo}

Os objetivos foram analisar a frequência de consumo de alimentos saudáveis e não saudáveis e diferenças no conhecimento e consumo de alimentos típicos brasileiros dos adolescentes da Região CentroOeste, comparando-a às demais regiões. Estudo transversal, desenvolvido com 10.514 adolescentes, com 13 e 14 anos de idade e que responderam ao questionário online. Os dados foram analisados por meio do programa estatístico SPSS, utilizando análise univariada para estimar frequência do consumo alimentar e teste de associação qui-quadrado para variáveis categóricas como conhecimento e consumo de alimentos nacionais. O nível de significância considerado foi de $5 \%$. Verificou-se alta frequência de consumo de alimentos marcadores de uma alimentação não saudável e baixa frequência de consumo de alimentos marcadores de uma alimentação saudável. Os adolescentes da Região CentroOeste apresentaram maior frequência de consumo de feijões e hortaliças e menor frequência de consumo de salgados fritos e biscoitos, com diferença significativa $(\mathrm{p}<0,001)$ para as outras regiões. Os alimentos nacionais foram amplamente conhecidos, com exceção para o cará, que apenas 32,1\% dos adolescentes da Região Centro-Oeste relataram conhecer. O consumo desses alimentos típicos foi bem variado e diferiu significativamente das outras regiões para cará, dobradinha, mandioca, arroz carreteiro, canjica e uva. Evidencia-se a necessidade de investigações mais específicas da presença dos alimentos nacionais no ambiente habitacional e de convívio e investigações no consumo que contemplem a realização da Segurança Alimentar e Nutricional.

Palavras-chave: Consumo Alimentar. Adolescentes. Hábitos Alimentares. Centro-Oeste. 


\section{Abstract}

The study aimed to analyze the frequency of consumption of healthy and unhealthy foods and differences in knowledge and consumption of typical Brazilian food among adolescents in the Midwestern region, comparing it to other regions. Cross-sectional study conducted with 10,514 adolescents, aged 13 and 14 years and who responded to the online questionnaire. Data were analyzed using SPSS statistical software, using univariate analysis to estimate the frequency of food consumption and association with chi-square test for categorical variables as knowledge and national food consumption. The level of significance was $5 \%$. We observed high frequency of food consumption markers of a unhealthy diet and low frequency of food consumption markers of a healthy diet. Adolescents from the Midwestern Region had higher frequency of consumption of beans and vegetables and lower frequency of consumption of fried snacks and biscuits, with significant difference $(p<0.001)$ for the other regions. National foods were widely known, except for the character, that only $32.1 \%$ of adolescents in the Midwest Region reported knowing. The typical consumption of these foods was well varied and differed significantly from other regions to yams, tripe, cassava, rice Wagoner, hominy and grape. Highlights the need for more specific investigations of the presence of food in the national housing and convivial atmosphere and investigations in consumption that include the achievement of Food and Nutritional Security.

Key words: Food Consumption. Adolescents. Food Habits. Midwest.

\section{Introdução}

A fase da adolescência é situada entre a infância e a vida adulta. Geralmente, os adolescentes são caracterizados pela busca da independência e da identidade própria, mudanças no perfil psicológico e hormonais, maior suscetibilidade à influência de amigos, da escola e da mídia. ${ }^{1} \mathrm{O}$ padrão alimentar desse grupo é caracterizado pela monotonia na escolha de alimentos, baixa ingestão de frutas e hortaliças, elevado consumo de alimentos com alta densidade energética ricos em açúcares e gorduras, não realização do café da manhã, entre outros. ${ }^{1,2}$

Dados da Pesquisa Nacional de Saúde do Escolar $^{3}$ confirmam esse padrão. Nela foram obtidos dados sobre o consumo alimentar de escolares do 9 o ano do ensino fundamental. Analisou-se 
elevado consumo de alimentos não saudáveis como frituras, biscoitos, bolachas, refrigerantes, guloseimas e embutidos, em contrapartida ao reduzido consumo de alimentos marcadores de uma alimentação saudável como feijão, frutas, hortaliças e leite.

Vale ressaltar que existem aspectos culturais referentes à alimentação, que são construídos ao longo do tempo e estão constantemente sujeitos a influências externas e internas ao indivíduo. A cultura de uma população pode ser compreendida pela caracterização das relações internas com atribuição de significados próprios às ações exercidas e utilização de símbolos. ${ }^{4}$

Influenciado pelas mudanças no modo de vida urbano, avanço das tecnologias, diversas campanhas publicitárias, fácil acessibilidade física e financeira aos alimentos, o padrão alimentar da população vem mudando e se adaptando a essas diversas circunstâncias. Entretanto, constatouse nos últimos anos relação entre o consumo alimentar e o surgimento de doenças crônicas não transmissíveis. ${ }^{5}$

Para a Organização Mundial da Saúde (OMS), o desenvolvimento de hábitos alimentares saudáveis ainda na infância e adolescência permite a perpetuação de bons hábitos na vida adulta e confere maior proteção para o desenvolvimento de doenças crônicas.${ }^{6,7} \mathrm{Em}$ vista de tais pontos, destaca-se a importância de conhecer o hábito alimentar da população adolescente, a fim de subsidiar intervenções nutricionais e educacionais de preservação de identidade alimentar e geração de condições de vida saudáveis e promotoras de saúde.

Os objetivos deste estudo são analisar a frequência de consumo de alimentos saudáveis e não saudáveis e diferenças no conhecimento e consumo de alimentos típicos brasileiros dos adolescentes da Região Centro-Oeste (CO) em comparação aos adolescentes das demais regiões do Brasil.

\section{Metodologia}

Foi realizado estudo do tipo transversal nas capitais brasileiras. O público estudado foram adolescentes do 9o ano do ensino fundamental, matriculados regularmente em escolas públicas e privadas. Os dados desse estudo fazem parte da pesquisa Mapeamento da cultura alimentar da população adolescente nas capitais brasileiras e no Distrito Federal, realizado no período de março de 2011 a dezembro de 2012.

O processo de amostragem foi por conglomerados em um único estágio, realizado de forma a gerar dados representativos para a população adolescente residente nas capitais da Região CentroOeste. Utilizou-se para o cálculo o erro máximo de 0,05 em valor absoluto e nível de confiança de 95\%. A amostra para as capitais do Centro-Oeste foi estimada em 3.978 estudantes, sendo $2.940 \mathrm{em}$ escolas públicas e 1.038 em escolas particulares. Os critérios de exclusão foram não preenchimento do questionário online e adolescentes com idade diferente de 13 ou 14 anos no período de coleta. 
As escolas públicas e particulares foram selecionadas aleatoriamente para a pesquisa, a partir do cadastro do Censo Escolar 2010 realizado pelo INEP/MEC. Após gerar essa lista aleatória, a equipe colaboradora entrou em contato com as escolas por meio de ligações telefônicas. Inicialmente, perguntava-se se a escola possuía laboratório de informática com acesso a internet, quantos alunos estavam matriculados no $9^{\underline{0}}$ ano/8 $8^{\underline{a}}$ série, quantos alunos eram frequentes e turno de estudo. Ao possuir o primeiro critério, a escola entrava para a amostra; quando não possuía, essa escola era descartada e a ligação era feita para a próxima da lista. As secretarias estaduais e/ou municipais colaboraram com a pesquisa, fornecendo apoio para a marcação das reuniões e primeiro contato com as escolas públicas. As escolas que compareceram à reunião já saíam com todas as informações necessárias para aplicação do questionário, inclusive com o Termo de Consentimento para os pais dos estudantes. A coleta era agendada escola por escola, de acordo com o número de alunos e disponibilidade da mesma.

Todas as capitais receberam a visita de dois nutricionistas da pesquisa, que realizaram uma reunião com os representantes das escolas selecionadas e das secretarias de Educação municipais e estaduais, a fim de transmitir informações necessárias para o acesso e preenchimento dos questionários. Os dados foram coletados por meio de questionário online, que continha os seguintes blocos de perguntas: características sócio-demográficas do entrevistado; questionário de frequência alimentar; e alimentos e preparações regionais.

O consumo alimentar abordava a frequência semanal de consumo de alimentos considerados como marcadores de alimentação saudável, segundo a Pesquisa Nacional de Saúde do Escolar (PeNSE) $)^{3}$ :-feijão, legumes ou verduras cruas e cozidas, salada crua, frutas e leite; e de alimentação não saudável: batata frita, salgados fritos, embutidos, biscoitos salgados, biscoitos doces, guloseimas e refrigerantes. O percentual de consumo de um alimento em cinco dias ou mais na semana foi utilizado como parâmetro de diagnóstico de uma alimentação saudável ou não saudável.

Em relação aos alimentos e preparações regionais, eram apresentadas ao aluno a imagem do alimento e questões sobre o conhecimento e consumo de tal alimento. As respostas eram prédefinidas em "sim" ou "não". Caso sua primeira opção fosse "sim", o sistema automaticamente gerava novas perguntas a respeito do mesmo alimento, investigando se o aluno consumia, como ele consome, com qual frequência e se ela gosta. Caso sua primeira opção fosse "não", perguntava-se se o aluno experimentaria e por que ele não comeria. Foram considerados o consumo e conhecimento de 12 alimentos e preparações nacionais, sendo eles: coco, uva, cará, mandioca, batata doce, couve manteiga, quiabo, cozido, dobradinha, Maria Izabel ou arroz carreteiro, mungunzá ou canjica e feijoada. Os alimentos nacionais utilizados para a pesquisa foram os descritos por Ginani ${ }^{8}$ como os mais comumente utilizados em todas as regiões brasileiras.

Os alunos responderam ao questionário no laboratório de informática da escola durante o período de aula. Foram excluídos da amostra adolescentes faltosos no dia da entrevista e 
adolescentes com alguma limitação que os impossibilitasse de responderem ao questionário online. Os responsáveis foram informados e assinaram Termo de Consentimento Livre e Esclarecido; as escolas assinaram o Termo de Ciência Institucional.

Foram feitas comparações entre os hábitos dos adolescentes da Região Centro-Oeste e os adolescentes das outras quatro regiões: Norte, Nordeste, Sudeste e Sul. O programa utilizado para as análises dos dados foi o SPSS versão 16.0 (SPSS Inc., Chicago, Estados Unidos), ferramenta para análise de dados utilizando técnicas estatísticas básicas e avançadas. As variáveis trabalhadas foram classificadas da seguinte forma: escalar (frequência de consumo alimentar) e nominal (conhecimento e consumo de alimentos e preparações nacionais). A análise univariada expressou a frequência das variáveis de consumo de alimentos saudáveis e não saudáveis entre os dois grupos sob a forma de proporções e com nível de significância de 5\%. Os testes de associação utilizados foram o qui-quadrado para variáveis categóricas, como conhecimento e consumo de alimentos nacionais. Foi realizada a associação dessas variáveis com as regiões analisadas (Centro-Oeste e demais capitais). O nível de significância considerado foi de $5 \%$.

\section{Resultados}

A amostra final foi composta por 10.514 adolescentes com média de idade de 14 anos (DP = 1,3 anos), sendo $55,6 \%$ do sexo feminino $(n=5850)$ e $44,4 \%$ do sexo masculino $(n=4.664)$. Na tabela 1, encontra-se o percentual de adolescentes que frequentavam o $9^{\underline{0}}$ ano do ensino fundamental e responderam o questionário.

Tabela 1. Percentual de escolares frequentando o 9o ano ensino fundamental por estado da Região Centro-Oeste e outras regiões. Mapeamento da cultura alimentar da população adolescente nas capitais brasileiras e no Distrito Federal, 2012.

\begin{tabular}{lcc}
\hline \multirow{2}{*}{$\begin{array}{c}\text { Munícipios das capitais e } \\
\text { Distrito Federal }\end{array}$} & $\begin{array}{c}\text { Percentual de escolares frequentando o 9o ano do } \\
\text { ensino fundamental por estado }\end{array}$ \\
\cline { 2 - 3 } Região Centro-Oeste & $\mathrm{n}$ & $\%$ \\
Brasília & 1.591 & 15,1 \\
Goiânia & 347 & 3,3 \\
Campo Grande & 591 & 5,6 \\
Cuiabá & 331 & 3,1 \\
Outras regiões & 322 & 3,1 \\
\hline
\end{tabular}


A escolaridade dos pais (tabela 2$)$ apresentou diferença significativa $(p<0,001)$ entre as regiões comparadas. Grande parte dos estudantes referiu não saber ou não informou a escolaridade do pai e da mãe. Pouco mais de um quarto dos estudantes referiram que os pais possuem ensino superior. As maiores prevalências de escolaridade ocorreram na Região Centro-Oeste.

Tabela 2. Escolaridade da mãe e do pai de adolescentes da região Centro-Oeste e outras capitais. Mapeamento da cultura alimentar da população adolescente nas capitais brasileiras e no Distrito Federal, 2012.

\begin{tabular}{lcccc}
\hline & \multicolumn{2}{c}{$\begin{array}{c}\text { Adolescentes da Região } \\
\text { Centro-Oeste }(\%)\end{array}$} & \multicolumn{2}{c}{$\begin{array}{c}\text { Adolescentes das outras } \\
\text { regiões (\%) }\end{array}$} \\
\hline Mãe & Pai & Mãe & Pai \\
Não estudou & 0,9 & 2,1 & 2 & 2,6 \\
Ensino Fundamental & 11,4 & 18,7 & 15,2 & 24 \\
Ensino Médio & 15,6 & 17,3 & 17,5 & 16 \\
Ensino Superior & 28 & 24,5 & 27,4 & 22,7 \\
Não informou/Não sabe & 44,1 & 37,4 & 38 & 34,7 \\
\hline
\end{tabular}

Consumo de alimentos marcadores de uma alimentação saudável

A tabela 3 apresenta o percentual de consumo dos alimentos marcadores de dieta saudável investigados em cinco dias ou mais da semana em escolares da Região Centro-Oeste e demais regiões brasileiras. 
Tabela 3. Percentual de escolares frequentando o $9^{\circ}$ ano do ensino fundamental com consumo alimentar de alimentos marcadores de dieta saudável e não saudável maior ou igual a cinco dias, nos últimos sete dias, na Região Centro-Oeste e outras regiões. Mapeamento da cultura alimentar da População Adolescente nas Capitais Brasileiras e no Distrito Federal, 2012.

\begin{tabular}{|c|c|c|c|}
\hline \multirow[t]{3}{*}{ Alimentos } & \multicolumn{3}{|c|}{ Região } \\
\hline & Centro-Oeste & Outras & \multirow{2}{*}{ Valor de $\mathrm{p}$} \\
\hline & $\%$ & $\%$ & \\
\hline \multicolumn{4}{|l|}{$\begin{array}{l}\text { Marcadores de dieta } \\
\text { saudável }\end{array}$} \\
\hline Feijão & 66,2 & 51,8 & $<, 001$ \\
\hline Hortaliças & 36,8 & 31,6 & $<, 001$ \\
\hline Hortaliças cruas & 40,1 & 26,7 & $<, 001$ \\
\hline Hortaliças cozidas & 10,4 & 12,3 & 0,021 \\
\hline Frutas & 36,8 & 37,8 & 0,690 \\
\hline Leite & 54,4 & 55,8 & 0,909 \\
\hline \multicolumn{4}{|l|}{$\begin{array}{l}\text { Marcadores de dieta } \\
\text { não saudável }\end{array}$} \\
\hline Batata frita & 5,9 & 7,1 & 0,139 \\
\hline Salgados fritos & 11,5 & 15,9 & $<0,001$ \\
\hline Embutidos & 20 & 22,9 & 0,116 \\
\hline Biscoitos salgados & 29,8 & 33,5 & 0,001 \\
\hline Biscoitos doces & 28 & 33,8 & $<0,001$ \\
\hline Guloseimas & 47,7 & 45,2 & 0,127 \\
\hline Refrigerante & 42,3 & 39,6 & 0,006 \\
\hline
\end{tabular}


O feijão teve maior percentual de consumo (66,2\%) pelos escolares, quando comparado com os outros alimentos marcadores de uma alimentação saudável na Região Centro-Oeste. Pôde-se observar que, nas outras regiões do país, o consumo de feijão $(51,8 \%)$ foi o segundo maior dentre os alimentos saudáveis, tendo consumo menor apenas que o marcador "leite". O consumo de leite em cinco dias ou mais pelos escolares nas demais capitais foi maior que os outros grupos, obtendo percentual de $55,8 \%$. As frutas foram consumidas em cinco dias ou mais por 36,8\% dos escolares na Região Centro-Oeste e por 37,8\% dos escolares no restante do país.

O consumo de hortaliças pôde ser observado conforme sua forma de preparo. Considerando o consumo alimentar maior ou igual a cinco dias, as hortaliças cozidas foram as menos consumidas pelos adolescentes da Região Centro-Oeste (10,4\%) e nas demais regiões (12,3\%). As hortaliças cruas tiveram maior consumo pelos escolares da Região Centro-Oeste (40,1\%), com diferença significativa $(p<0,001)$ para os escolares das demais regiões $(26,7 \%)$.

\section{Consumo de alimentos marcadores de uma alimentação não saudável}

Dentre os alimentos marcadores de uma alimentação não saudável (tabela 3), o consumo de salgados fritos e de biscoitos doces obteve diferença significativa entre as amostras comparadas. $\mathrm{O}$ consumo desses alimentos pelos adolescentes da Região Centro-Oeste é menor que dos adolescentes das outras regiões.

Com relação aos alimentos marcadores de uma alimentação não saudável, os maiores percentuais de consumo foram para guloseimas e refrigerantes. Na Região Centro-Oeste, 47,7\% dos escolares responderam consumir em cinco dias ou mais na semana. No restante do país, o consumo foi representado por $45,2 \%$ dos escolares. O consumo de refrigerantes foi de 42,3\% na Região Centro-Oeste e de 39,6\% nas demais.

O consumo de biscoitos doces foi menor na Região Centro Oeste (28\%) que nos demais estados (33,8\%), assim como o consumo de biscoito salgados, 29,8\% e 33,5\%, respectivamente. Os embutidos foram consumidos por $20 \%$ dos escolares da Região Centro-Oeste e 22,9\%, dos escolares do restante do país.

O consumo de batata frita em cinco dias ou mais foi de 5,9\% e de salgados fritos, $11,5 \%$ nas capitais da Região Centro-Oeste. Para os demais estados, constatou-se maior consumo de batata frita $(7,1 \%)$ e salgados fritos $(15,9 \%)$ pelos escolares. De modo geral, notou-se que o consumo de guloseimas e refrigerantes foi maior que o de frutas e hortaliças nas duas áreas do país analisadas. A figura 1 mostra a variabilidade na frequência nos últimos sete dias de consumo dos alimentos marcadores de alimentação saudável e não saudável na Região Centro Oeste e nas outras regiões, respectivamente. 


\section{Região Centro Oeste}

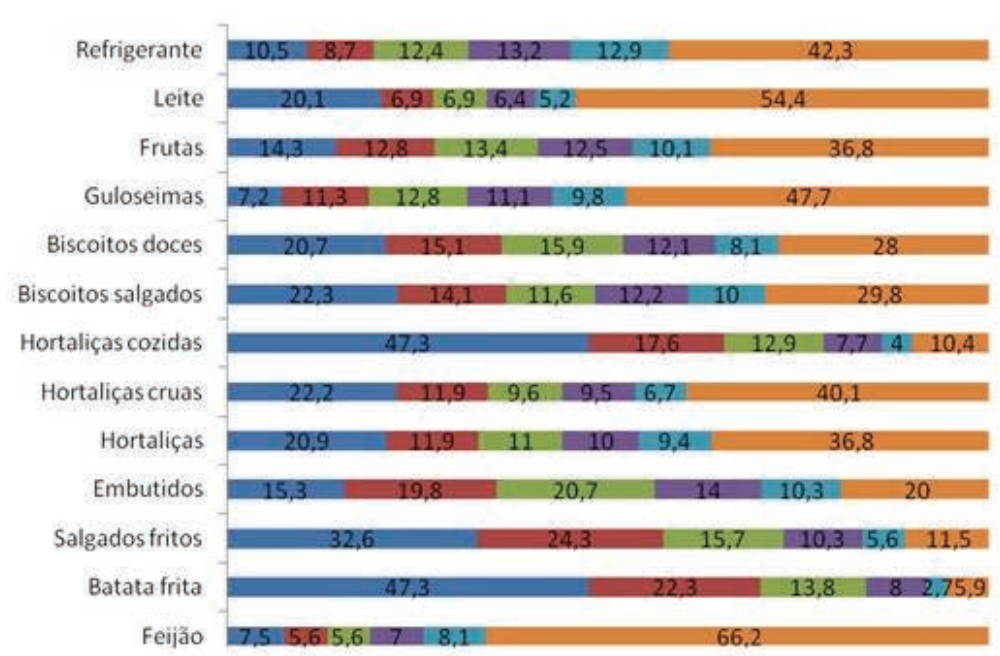

\section{Outras regiōes}

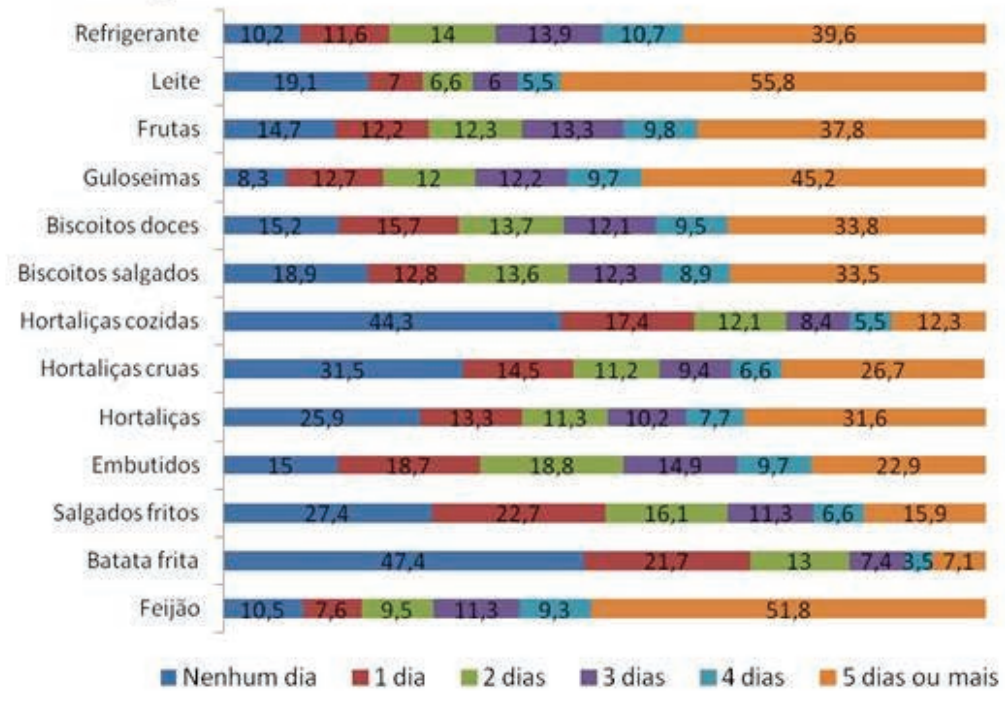

Figura 1. Percentual de escolares frequentando 9o ano do ensino fundamental, por consumo alimentar habitual, segundo o alimento consumido nas capitais da Região Centro-Oeste e outras regiões -2012 . 


\section{Conhecimento e consumo de alimentos e preparações nacionais}

Constatou-se diferença significativa no conhecimento em sete dos 12 alimentos e preparações nacionais apresentados entre escolares da Região Centro-Oeste e das demais capitais brasileiras (tabela 4). O percentual de conhecimento foi maior na Região Centro Oeste paras os seguintes alimentos: cará $(32,1 \%)$, couve manteiga $(81,1 \%)$, Dobradinha $(61,8 \%)$, mandioca ou aipim ou macaxeira (82\%), canjica $(89,5 \%)$ e uva $(89 \%)$. O cará, por sua vez, foi o alimento destacado por ter o menor percentual de conhecimento nas duas áreas analisadas.

Os alimentos menos consumidos pelos escolares da Região Centro-Oeste foram mandioca $(11,4 \%)$, cará $(15 \%)$, dobradinha $(26,1 \%)$ e uva $(35,3 \%)$. Entre as duas áreas estudadas, observouse diferença no consumo de cará, couve manteiga, cozido, dobradinha, feijoada, mandioca, carreteiro, canjica e uva $(\mathrm{p}<0,005)$. Os alimentos e preparações com maior percentual de escolares que os consomem foram coco $(89,4 \%)$, arroz carreteiro $(88,2 \%)$, canjica $(79,2 \%)$ e feijoada $(79,1 \%)$, nas capitais da Região Centro-Oeste (tabela 4). Para as demais regiões do país, os alimentos e preparações com maior percentual de escolares que os consomem foram coco $(87,7 \%)$, feijoada $(82,6 \%)$ e arroz carreteiro $(78,9 \%)$. Dentre os alimentos que tiveram diferença estatística significante

$(\mathrm{p}<, 005)$ entre as regiões e apresentaram baixo consumo, estão cará, couve manteiga, dobradinha, mandioca e uva. 
Tabela 4. Percentual de escolares frequentando o $9 \underline{0}$ ano do ensino fundamental que conhecem ou não e consomem ou não os alimentos e preparações nacionais apresentadas, na região Centro-Oeste e outras regiões do Brasil. Mapeamento da cultura alimentar da População Adolescente nas Capitais Brasileiras e no Distrito Federal, 2012.

\begin{tabular}{|c|c|c|c|}
\hline \multirow{3}{*}{$\begin{array}{c}\text { Alimento ou } \\
\text { preparação nacional }\end{array}$} & \multicolumn{3}{|c|}{ Região } \\
\hline & Centro-Oeste & Outras & \multirow{2}{*}{ Valor de $\mathrm{p}$} \\
\hline & Percentual (\%) & Percentual (\%) & \\
\hline \multicolumn{4}{|l|}{ CONHECEM } \\
\hline Batata doce & 91,6 & 91,9 & 0,806 \\
\hline Cará & 32,1 & 28 & 0,002 \\
\hline Coco & 97,9 & 97,7 & 0,724 \\
\hline Couve manteiga & 81,1 & 67,4 & $<0,001$ \\
\hline Cozido & 77,8 & 81 & 0,012 \\
\hline Dobradinha & 61,8 & 56,4 & $<0,001$ \\
\hline Feijoada & 95,7 & 96,9 & 0,001 \\
\hline Mandioca & 82 & 57,1 & $<0,001$ \\
\hline Arroz carreteiro & 94,8 & 93,7 & 0,193 \\
\hline Canjica & 89,5 & 68,4 & $<0,001$ \\
\hline Quiabo & 86,5 & 88 & 0,232 \\
\hline Uva & 89 & 83,8 & $<0,001$ \\
\hline \multicolumn{4}{|l|}{ CONSOMEM } \\
\hline Batata doce & 54,4 & 57,7 & 0,044 \\
\hline Cará & 15 & 16,5 & $<0,001$ \\
\hline Coco & 89,4 & 87,7 & 0,138 \\
\hline Couve manteiga & 55,2 & 38,9 & $<0,001$ \\
\hline Cozido & 57 & 59,9 & 0,011 \\
\hline Dobradinha & 26,1 & 26,6 & $<0,001$ \\
\hline Feijoada & 79,1 & 82,6 & 0,001 \\
\hline Mandioca & 11,4 & 6,9 & $<0,001$ \\
\hline Arroz carreteiro & 88,2 & 78,9 & $<0,001$ \\
\hline Canjica & 79,2 & 56,7 & $<0,001$ \\
\hline Quiabo & 63,3 & 65,6 & 0,165 \\
\hline Uva & 35,3 & 30,7 & $<0,001$ \\
\hline
\end{tabular}




\section{Discussão}

Este estudo apresentou predominância do sexo feminino, idade média de 14 anos e escolaridade materna e paterna variada. Devido aos critérios de exclusão da amostra e número de respondentes menor que o estimado, a amostra final do estudo contou com 10.514 adolescentes, sendo 1.591 da Região Centro-Oeste e 8.923 das outras regiões, sem prejuízo da representatividade regional.

Os dados obtidos na pesquisa Mapeamento da Cultura Alimentar da População Adolescente nas Capitais Brasileiras e no Distrito Federal, de 2012, permitiram conhecer o consumo alimentar habitual, o conhecimento e consumo de alimentos e preparações nacionais por de adolescentes com idade de 13-14 anos.

As diretrizes nacionais sobre alimentação saudável preconizam a importância e necessidade do consumo diário de frutas, hortaliças, leite, carne e leguminosas, e a necessidade de evitar o consumo de guloseimas, refrigerantes, biscoitos e frituras. Práticas alimentares saudáveis, quando incorporadas ao comportamento desde a juventude, contribuem para a promoção da saúde na vida adulta, além de reduzir o risco de desenvolver doenças crônicas não transmissíveis. ${ }^{6}$ Além disso, a preservação cultural alimentar é um pressuposto da Lei nº 11346, que define o conceito de segurança alimentar e nutricional no Brasil. ${ }^{9}$ Não existe, portanto, segurança alimentar sem respeito às práticas culturais. O próprio Guia Alimentar Brasileiro traz como conceito de alimentação saudável o respeito às praticas alimentares regionais. ${ }^{6}$ Daí a importância de verificar o conhecimento e consumo destes alimentos, tradicionalmente brasileiros, entre a população adolescente.

Os resultados da PeNSE de 2012, ${ }^{3}$ que investigou população semelhante à desta pesquisa, apontaram um padrão de consumo alimentar entre os escolares caracterizado pelo alto consumo de frituras, guloseimas, embutidos, biscoitos, bolachas e baixo consumo de feijão, frutas, hortaliças e leite. Esse padrão é compatível com os resultados observados neste trabalho e, muitas vezes, mais evidente entre adolescentes da Região Centro-Oeste, quando comparados às demais. O consumo de refrigerantes em mais de cinco dias na semana, por exemplo, foi maior nesta região $(\mathrm{p}<0,006)$, sendo praticado por $42,3 \%$ da amostra.

O feijão é um alimento de bom valor nutricional pelo alto teor de fibras, proteínas, ferro e ácido fólico, e é consumido diariamente por mais da metade dos adolescentes. O consumo de feijão em cinco dias ou mais na semana na Região Centro-Oeste $(66,2 \%)$ foi maior que nas demais regiões. O maior consumo nessa região, pela população, é compatível com o verificado pela Vigilância de Fatores de Risco e Proteção para Doenças Crônicas por Inquérito Telefônico (Vigitel) de 2006 a 2009. ${ }^{10}$ De acordo com a PeNSE (2012) ${ }^{3}$, o consumo de feijão pelos escolares em cinco dias ou mais na semana $(69,9 \%)$ é um indicador de proteção à saúde. 
Segundo a Pesquisa de Orçamentos Familiares (POF) 2008-2009, ${ }^{11}$ a Região Centro-Oeste apresentou consumo médio per capita de arroz, feijão, carne bovina e leite integral maior que as demais regiões, alimentos marcadores de uma alimentação saudável. No presente estudo, o consumo de feijão foi maior na Região Centro-Oeste, mas o consumo de leite foi menor, mas sem diferença significativa. O consumo de arroz e carne não fez parte desta pesquisa.

Apesar do baixo consumo diário de leite observado, ele representa um hábito alimentar saudável entre escolares. Possui na sua composição cálcio, micronutriente importante no processo de mineralização óssea durante a puberdade. Estudo realizado com adolescentes paulistas constatou que o consumo de leite e derivados é responsável por 56,5\% do cálcio dietético presente na alimentação dos adolescentes. ${ }^{12}$ Portanto, a ingestão de leite contribui para uma vida saudável e deve ser estimulada sobretudo nessa faixa etária, uma vez que ainda está aquém do recomendado.

O baixo consumo de frutas e hortaliças observado nos adolescentes é semelhante ao de adultos, menor do que o recomendado. ${ }^{13}$ A OMS recomenda a ingestão mínima de $400 \mathrm{~g}$ de frutas e hortaliças diariamente. ${ }^{14}$ Nesta pesquisa não foram abordadas as porções consumidas, somente a frequência de consumo semanal, o que salienta ainda mais a distância da ingestão recomendada, uma vez que apenas $37 \%$ dos adolescentes consomem frutas cinco dias ou mais na semana. Apesar de esse dado ainda ser insatisfatório, é maior que o percentual observado na $\mathrm{PeNSE}^{3}$, onde apenas 30,2\% dos adolescentes tinham esse comportamento.

Os alimentos marcadores de uma alimentação não saudável estão presentes no cotidiano dos adolescentes. O alto consumo de guloseimas, biscoitos, refrigerantes e frituras observado neste estudo já foi diagnosticado anteriormente, revelando ser uma tendência nacional e global..$^{13,15}$ Esse diagnóstico é relevante porque permite subsidiar ações futuras do Ministério da Saúde dentro da promoção da Alimentação Saudável. ${ }^{16}$

Em relação ao conhecimento de alimentos e preparações nacionais, constatou-se que a maioria dos escolares frequentando o 9 o ano, tanto na Região Centro-Oeste e das demais capitais, reconhecem com frequência a maioria desses alimentos. A exceção foi o cará, que apresentou baixo conhecimento em todas as regiões. O conhecimento dos alimentos nacionais pelos adolescentes da Região Centro-Oeste foi mais elevado que nas demais capitais de forma significativa, mas não foram encontrados estudos que abordassem tais aspectos, anteriores a esta pesquisa. Pode ter colaborado para a diferença observada a heterogeneidade do grupo ao qual a Região CentroOeste foi comparada. Os dados das regiões Norte, Nordeste, Sudeste e Sul foram agrupados - assim, as particularidades de cada região foram misturadas. Os pais da Região Centro-Oeste apresentaram também maior escolaridade que as demais, podendo ser isto um fator que propicie maior conhecimento desses alimentos, uma vez que escolaridade é proxy de renda e pode determinar exposição facilitada a vários tipos de alimentos. ${ }^{17}$. 
Ainda em relação ao caso dos alimentos nacionais pouco consumidos, o cará é um tubérculo do mesmo grupo da mandioca e do inhame, apresenta cultivo nacional e é de fácil acesso. No entanto, poucos adolescentes relataram consumi-lo, dado compatível com o baixo conhecimento do mesmo, observado nesste estudo. Não foram encontrados estudos que justificassem o baixo consumo e conhecimento do cará. O consumo de mandioca também foi muito baixo, resultado não esperado, uma vez que este alimento faz parte da cultura alimentar brasileira, é bem conhecido, de fácil plantio e aquisição. ${ }^{18} \mathrm{~A}$ dobradinha é uma preparação regional que contém como ingredientes principais o bucho bovino e o feijão branco. Foi a preparação com menor consumo pelos adolescentes, provavelmente por uma rejeição em relação aos aspectos sensoriais característicos da preparação, componentes imprescindíveis para uma boa aceitação. ${ }^{19}$

A uva, por sua vez, é uma fruta amplamente conhecida e com baixo consumo por esse grupo, possivelmente devido a seu custo financeiro elevado e difícil acesso em algumas regiões. Salientase que a escolha alimentar é influenciada por diversos fatores, dentre os quais se destacam o fator econômico, a facilidade de aquisição, hábitos alimentares e aspectos sensoriais ${ }^{8}$. Além da questão geográfica e financeira, a escolha alimentar é influenciada pela valoração do alimento pelo consumidor e pelo grau de liberdade de cada indivíduo para realizar suas escolhas..$^{20,21}$

Para compreender melhor esses resultados, é fundamental também conhecer o motivo pelo qual o indivíduo não consome determinado alimento: seja ele o fato de não gostar, não ter acesso, não ter preço acessível, o alimento não ter sido a ele apresentado ou influência de outras pessoas ou do ambiente em que vive. ${ }^{20}$ A pesquisa Mapeamento da cultura alimentar da população adolescente nas capitais brasileiras e no Distrito Federal, cujos dados foram base deste estudo, teve caráter bem mais amplo e levou em consideração estes aspectos, porém não analisados no presente estudo.

\section{Conclusão}

O resultado deste trabalho indica alta frequência de consumo de alimentos marcadores de uma alimentação não saudável (frituras, embutidos, biscoitos salgados e doces, guloseimas e refrigerantes) e baixa frequência de consumo de alimentos marcadores de uma alimentação saudável (feijão, hortaliças, frutas e leite). Os escolares da Região Centro-Oeste apresentaram maior consumo de feijão e hortaliças que as demais regiões e menor consumo de salgados fritos e biscoitos, pontos positivos para composição de uma alimentação saudável. Os alimentos nacionais são amplamente conhecidos em sua maioria, mas há necessidade de investigações mais específicas sobre a presença de tais alimentos no cotidiano deste público.

Diversos alimentos e preparações nacionais obtiveram baixo consumo ou consumo não satisfatório. Em vista disso, destaca-se a importância de realizar análises mais complexas que 
levem em consideração os pressupostos da Segurança Alimentar e Nutricional. Ações que visem ao resgate e à manutenção de praticas alimentares saudáveis e culturalmente adequadas devem ser estimuladas, uma vez que alimentar-se tem significado social e cultural. O corpo precisa de nutrientes, porém, consumimos alimentos.

\section{Referências}

1. Fisberg M, Bandeira CRS, Bonilha EA, Halpern G, Hirschbruch MD. Hábitos alimentares na adolescência. Pediatr. Mod. 2005; 36(11):724-734.

2. Pedrinola F. Nutrição e transtornos alimentares na adolescência. Pediatr. Mod. 2002; 38(8):377-380.

3. Instituto Brasileiro de Geografia e Estatística. Pesquisa nacional de saúde do escolar. Rio de Janeiro: IBGE; 2012.

4. Geertz CA. Interpretação das culturas. Rio de Janeiro: LTC; 1989.

5. Garcia RWD. Reflexos da globalização na cultura alimentar, considerações sobre as mudanças na alimentação urbana. Rev. Nutr. 2003; 16(4):483-92.

6. Brasil. Ministério da Saúde. Guia alimentar para a população brasileira: promovendo a alimentação saudável. Brasília: Ministério da Saúde; 2006.

7. Currie C, Gabhainn SN, Godeau E, Roberts C, Smith R, Currie D, et al. Inequalities in young people's health: health behaviour in school-aged children international report from the 2005/2006 survey. Copenhagen: World Health Organization; 2008. Health policy for Children and adolescents, n. 5.

8. Ginani VC. Avaliação da qualidade nutricional, sensorial, cultural de cardápios populares [tese]. Brasília: Universidade de Brasília; 2011.

9. Brasil. Lei no 11.346, de 15 de setembro de 2006. Lei Orgânica de Segurança Alimentar e Nutricional. Institui o Sistema Nacional de Segurança Alimentar e Nutricional a fim de assegurar direito humano à alimentação adequada para toda população brasileira. Diário Oficial da União. 2006.

10. Velasquez-melendez, G et al. Tendências da frequência do consumo de feijão por meio de inquérito telefônico nas capitais brasileiras, 2006 a 2009. Cienc. Saúde Coletiva. 2012; 17(12):3363-3370.

11. Instituto Brasileiro de Geografia e Estatística. Pesquisa de orçamentos familiares: análise do consumo alimentar pessoal no Brasil. Rio de Janeiro: IBGE; 2011.

12. Lerner BR, Lei DLM, Chaves SP, Freire RD. O cálcio consumido por adolescentes de escolas públicas de Osasco, São Paulo. Rev. Nutr. 2000; 13(1):57-63.

13. Souza AM, Pereira RA, Yokoo EM, Levy RB, Sichieri R. Alimentos mais consumidos no Brasil: inquérito nacional de alimentação 2008/2009. Rev. Saúde Publ. 2013; 47(Supl. 1):190S-199S.

14. World Health Organization. Diet, nutrition and the prevention chronic diseases. Geneva: WHO; 2003. 
15. Carmo MB, Toral N, Silva MV, Slater B. Consumo de doces, refrigerantes e bebidas com adição de açúcar entre adolescentes da rede pública de ensino de Piracicaba, São Paulo. Rev. Bras. Epidemiol. 2006; 9(1):121-30.

16. Barreto SMP, Oliveira AR, Sichieri R, Monteiro CA, Filho MB, Schimidt MI, et al. Análise da estratégia global para alimentação saudável, atividade física e saúde. Epidemiologia e Serviços de Saúde. 2005; 14(1):41-68.

17. Claro RM, Monteiro CA. Renda familiar, preço de alimentos e aquisição domiciliar de frutas e hortaliças no Brasil. Rev. Saúde Pública 2010; 44(6):1014-20.

18. Brasil. Ministério da Saúde. Alimentos regionais brasileiros. Brasília: Ministério da Saúde; 2002.

19. Silva I, Pais-Ribeiro JL, Cardoso H. Porque comemos o que comemos: Determinantes psicossociais da selecção alimentar. Psic. Saúde \& Doenças. 2008; 9(2):189-208.

20. Jomori MK, Proenca RPC, Calvo MCM. Determinantes de escolha alimentar. Rev. Nutr. 2008; 21(1):63-73.

21. Connors M, Bisogni CA, Sobal J, Devine CM. Managing values in personal food systems. Appetite. 2001; 36(3):189-200. 